This item was submitted to Loughborough's Research Repository by the author.

Items in Figshare are protected by copyright, with all rights reserved, unless otherwise indicated.

\title{
Repeat personal victimization: 'boosts' or 'flags'?
}

PLEASE CITE THE PUBLISHED VERSION

PUBLISHER

(C) OUP

LICENCE

CC BY-NC-ND 4.0

\section{REPOSITORY RECORD}

Tseloni, Andromachi, and Ken Pease. 2019. “Repeat Personal Victimization: 'boosts' or 'flags'?". figshare. https://hdl.handle.net/2134/894. 
BRIT. J. CRIMINOL. (2003) 43, 196-212

\title{
REPEAT PERSONAL VICTIMIZATION
}

\author{
'Boosts' or 'Flags'?
}

\section{Andromachi Tseloni and Ken Pease*}

Repeat victimization has recently featured prominently in crime reduction research, especially in the UK. Crime prevention efforts which focus on repeats have enjoyed some success. Yet little is known about what generates repeat victimization. While this remains the case, the scope for crime reduction through the prevention of repeated events against the same target will be limited. There is general agreement about the potential relevance of two intertwined theoretical causes, namely event dependence (where the crime event boosts the probability of repetition), and heterogeneity (where the crime event flags an enduring risk, which enduring risk makes repetition likely). This paper attempts to disentangle the effects of event dependence and heterogeneity on repeat personal victimizations across three interviewing periods using the 1994 National Crime Victimization Survey. We employ a (fixed effects random intercept) multilevel model of personal crime counts incorporating individual and household characteristics as well as lifestyle and prior non-victimization of individuals clustered within households. Our results show that victimization by personal crime, especially over successive time periods, is partly due to measured heterogeneity. Personal crimes experienced by members of the same household are moderately but persistently correlated. This suggests that unmeasured heterogeneity is also implicated in period-to-period repetition of personal crime. The combined effects of unmeasured and measured heterogeneity do not exhaust the predictivity of prior for subsequent victimization, meaning that a degree of event dependence is involved.

Victimization is a good, arguably the best readily available, predictor of future victimization. This appears a robust finding across crime types and data sources (Farrell and Pease 2001). Concentrating crime reductive effort on those recently victimized has the dual advantage of allocating effort according to risk, and combining the functions of crime prevention and victim support (Pease 1998). While such an approach has enjoyed some success (see Pease 1998) the understanding of the process whereby repetition comes about limits the power of an approach based on the prevention of repeats. Two general categories of explanation have been proferred, as outlined below.

Event dependence implies that an initial victimization increases the probability of a subsequent event. The successful completion of a first crime renders the target more vulnerable and/or attractive. In principle the longer the victimization history, the closer to certainty is the probability of suffering a subsequent crime.

\footnotetext{
* Respectively, Department of Sociology, Aegean University, Limnou 1 \& Archipelagous, Mytilene 81100, Greece; Jill Dando Institute, University College London WC1E 6BT, UK, where correspondence should be addressed. Tel: 0207324 300; fax: 0207324 3003. This study was partly undertaken with the financial support of the American Statistical Association, Committee on Law and Justice Statistics (MD 971015-8688-360201). The authors would like to thank Dr Catherine Gallagher and Ms Erica Dinger for research assistance.
} 
Heterogeneity implies that individuals or households have constant chances of being victimized which are not affected by their victimization history. Some targets are repeatedly victimized because they have always been more attractive to offenders compared to other potential targets. Empirical modelling captures some of this heterogeneity in the estimated effects of any demographic, socio-economic and other characteristics of the unit of analysis, i.e. individuals or households, and their lifestyle. The set of such effects may be called measured heterogeneity. Some heterogeneity inevitably remains unexplained. Unexplained heterogeneity implies that 'two [individuals, for instance,] face [victimization] risks which are systematically different from each other even when these [individuals] have identical measured characteristics' (Osborn and Tseloni 1998: 308).

We are aware of three studies (Lauritsen and Davis-Quinet 1995; Osborn and Tseloni 1998; Wittebrood and Nieuwbeerta 2000) that have sought to disentangle the effects of event dependence ${ }^{1}$ and heterogeneity in repeat victimization via quantitative empirical models. The study of Lauritsen and Davis-Quinet (1995) uses the first five waves of the National Youth Survey of the United States and models the natural logarithm of the total number of reported victimizations (plus 1) via Generalized Least Squares. They find that both event dependence and heterogeneity affect current victimization. However there was strong evidence that relevant individual characteristics were not captured by the variables in their models (Lauritsen and Davis-Quinet 1995: 161). Wittebrood and Nieuwbeerta (2000) employ a retrospective life-course Dutch national crime survey to study victimization risk per year over the life course. They used a multilevel logit model of the probability of being victimized over one year and find that the effects of victimization on becoming a victim in a subsequent year are due to population unexplained heterogeneity rather than event dependence. The first two studies are very similar in approach. They estimate models of current victimization with and without prior victimization and then test the change in rho, an indicator of persistent unexplained heterogeneity. Osborn and Tseloni (1998) studied heterogeneity and event dependence contributions to property crime counts using the negative binomial model with data from the 1992 British Crime Survey. In their work, event dependence refers to the effects of prior victimization by various crime types over roughly five years prior to the reference period on the mean number of property crimes over the period of just over one year used in the survey. They find strong evidence of both event dependence and population unexplained heterogeneity in accounting for the effects of household and area characteristics. They also show that modelling crime counts rather than the victim/non-victim dichotomy predicts the entire distribution of victimization incidents and explicitly accounts for the crime concentration previously identified by descriptive studies (Ellingworth et al. 1995; Farrell 1992). The negative binomial model estimates event dependence across periods via the coefficient of prior victimization and within the reference period via its (constant) transition probabilities from one event to the next (Pease $e t$ al. 2001).

In this study we attempt to disentangle the effects of event dependence and heterogeneity on personal victimization counts, defining measured heterogeneity according to

\footnotetext{
${ }^{1}$ We use the term event dependence rather than state dependence, which has prevailed in the literature, in order to avoid confusion with the term state dependence upon the welfare system.
} 
routine activity or lifestyle theory. In particular, we model personal crime counts over a number of individual and household characteristics, individuals' lifestyle indicators and (lack of) personal victimization history over two survey waves prior to the reference period, namely during six months prior to the reference period and during the six months before that. The last set of covariates accounts for event dependence. ${ }^{2}$ If the estimated coefficient of prior non-victimization at wave 1 turns out to be statistically significant then (lack of) victimization history 12 to 18 months before the reference period affects the number of personal crimes experienced during the survey's reference period of six months (wave 3). This would imply event dependence across periods on average one year apart. Lack of statistical significance would, by contrast, imply that the previous year's victimization is unrelated to personal crimes experienced during the reference period. Similarly, lack of statistical significance of the estimated coefficient of (lack of) victimization 6 to 12 months (wave 2) before the survey's reference period would imply no event dependence in the short-run. With no statistically significant effects of prior victimization, the event dependence hypothesis could be rejected. Personal victimization would solely be due to the individuals' and their households' characteristics and lifestyle. To our knowledge, this is the first quantitative modelling study that investigates graded effects of event dependence, i.e. during two consecutive periods prior to the reference one. It would thus be interesting to see whether the effect of prior personal non-victimization on present victimization incidence weakens, remains constant or increases as one moves further back from the reference period.

The data come from the public use file of the 1994 US National Crime Victimization Survey after having reconstructed its original panel design at the person level. ${ }^{3}$ We employ a multilevel version of the negative binomial regression model in order to account for the contextual hierarchy in the data, namely individuals (level 1) clustered within households (level 2). This, aside from other advantages (see for instance Goldstein 1995; Bryk and Raudenbush 1992), allows for estimating any unexplained heterogeneity between households as well as between individuals (Tseloni 2000). Thus the relationship of both sources of heterogeneity with event dependence can be investigated. Further we calculate the intra-household correlation. This gives the proportion of the total variance which represents between household variation (Goldstein 1995: 19; see also the section entitled 'The Statistical Model' below). In other words it gives the correlation between personal crime incidence of two individuals from the same household after having accounted for the effects of their individual characteristics. The intra-household correlation implies persistent household unexplained heterogeneity.

To sum up, this work attempts to expand current knowledge of repeat victimization in three ways. It models crime counts and thus crime concentration across a large number of known individual and household characteristics as well as graded victimization history. It tests the relationship between event dependence and unexplained heterogeneity at both individual and household levels. It introduces and estimates the intra-household correlation of mean personal crimes.

\footnotetext{
${ }^{2}$ As mentioned, this is event dependence across periods which have been the focus of quantitative studies to date.

${ }^{3}$ The NCVS is a panel of housing units. However for the purposes of this study a person level panel has been retained (see the section concerning data).
} 
The following section presents the data set employed in this study. The section below concerning variables discusses the dependent variable, personal crime victimization, and the set of independent variables of our empirical models. Their statistical specification is described in the 'Statistical Model' section. This is followed by the section presenting the results of our analysis. The paper ends with conclusions.

\section{The Data}

The data for this study came from the 1994 National Crime Victimization Survey (henceforth NCVS). The NCVS is conducted by the US Census Bureau on behalf of the Bureau of Justice Statistics. It uses a rotating panel of housing units drawn from the Address List of the Decennial Census. All residents aged 12 or above in the selected housing units participated in the survey. Thus the NCVS sample represents in principle the population of non-institutionalized US permanent residents aged 12 years or more. The selected housing units remain in the survey for three and a half years and their residents are interviewed every six months. The first interview is used only as a benchmark, thereafter being discarded to avoid forward telescoping in crime reporting. There are thus a total of six waves of interviews with the residents of each selected housing unit, which remain available for general research. The survey collects information on respondents' victimization with details surrounding any reported incident, socio-demographic characteristics, lifestyle and respondent attitudes towards crime and the criminal justice system. The reference period for any reported crime is the time elapsed between two interviews, i.e. six months.

The 1994 NCVS contains three waves of interviews between January 1994 and June 1995, covering respectively the periods January to June 1994 (first wave), July to December 1994 (second wave) and January to June 1995 (third wave). The sample for this study consists of respondents from all the households participating in the 1994 NCVS for at least two waves, as well as one household from the selected housing units, which were occupied by three different households during the survey. ${ }^{4}$ The reference period is the six-month period about which each respondent was last interviewed, i.e. wave 3 . Interviews at waves 1 and 2 are only used in the models to define prior victim/non-victim status of the respondent and thereby estimate event dependence. All other explanatory variables (see the section on measured heretogeneity below) are concurrent to the last interview, i.e. refer to the state of affairs during wave 3 .

Table 1 gives the distribution of individuals per household in the final 1994 NCVS sample for this study. This natural clustering of individuals within households provides the basis for a 2-level model of personal crimes.

\footnotetext{
${ }^{4}$ Thus, each selected housing unit is represented once. The original sampling design of the survey has been preserved in this study while its focus has moved to the household rather than the housing unit.
} 
TABLE 1 Number of individuals (level 1) 12 years old or older per household (level 2)

\begin{tabular}{lc}
\hline Number of individuals & Frequency \\
\hline 1 & 13,109 \\
2 & 40,512 \\
3 & 17,606 \\
4 & 10,876 \\
5 & 3,434 \\
6 & 1,053 \\
7 & 275 \\
8 & 60 \\
9 & 39 \\
10 & 26 \\
11 & 9 \\
Total & 86,999 \\
\hline
\end{tabular}

The Variables

\section{Personal victimization}

The dependent variable in this study is the number of personal crimes experienced during six months prior to the last interview of the 1994 NCVS. Personal crime, $Y_{i j}$ with values $y_{i j}=0,1, \ldots$ for the $i$-th individual of the $j$-th household, is an aggregate count of rape, sexual assault, robbery, assault, threats, pocket-picking and larceny. Most events refer to assaults and threats, with assaults outnumbering threats. Table 2 gives the observed distribution of personal crimes reported at the third wave of the 1994 NCVS as well as their mean and variance. As one can see, risk of personal victimization is 2.2 per cent. 18 per cent of those victimized suffer repetition during the reference period. ${ }^{5}$ The

TABle 2 Personal crimes (wave 3)

\begin{tabular}{lrr}
\hline Number of crimes & Frequency & $\%$ \\
\hline 0 & 86,047 & 97.8 \\
1 & 1,660 & 1.9 \\
2 & 219 & .3 \\
3 & 46 & .1 \\
4 & 21 & .0 \\
5 & 5 & .0 \\
6 & 1 & .0 \\
Total & 86,999 & 100 \\
Mean & 0.0027 & \\
Variance & 0.0039 & \\
\hline
\end{tabular}

\footnotetext{
${ }^{5}$ Observed repeat victimization is in fact higher than this. Series have been included as one incident to conform with the NCVS practice (Lynch and Tseloni 2001).
} 
distribution is clearly overdispersed, with variance higher than its mean and therefore the negative binomial regression model, which allows for extra-Poisson variation (Cameron and Trivedi 1986; McCullagh and Nelder 1989), is appropriate for modelling personal crimes. As mentioned, here we employ a multilevel version of the negative binomial regression model (see the section 'Statistical Model' below) to account for the hierarchy in the data (Goldstein 1995; Goldstein et al. 1998).

\section{Indicators of event dependence}

The NCVS is a panel of housing units with minimal non-response (Lynch and Tseloni 2001). It suffers from attrition ${ }^{6}$ at the household and person level due to high population mobility. Indeed a declining proportion of respondents who participated in the third wave of the 1994 NCVS had participated in the two previous waves, 2 and 1 . Thus the aspiration of this study to identify what may be termed chronic victims i.e. those victimized during the third wave of the 1994 NCVS who had also reported crimes at the first and/or second waves of the survey, cannot be realized. Table 3 shows how many wave 3 respondents participated in the 1994 NCVS prior to January 1995 and the observed distribution of victimization. It also presents the distribution of our sample as non-victims, victims or non-responses across waves 1 and 2 in the 1994 NCVS. As seen, 95.4 and 28.7 per cent of the wave 3 respondents did not participate at waves 1 and 2, respectively. Thus in the last column and row of Table 3 'Other' refers predominantly to missing responses.

An indicator of non-victimization at waves 2 and 1 in the models below gives, respectively, the effects of not being victimized during $6<12$ months and $12<18$ months prior to the current reference period on personal crimes reported at wave 3 , i.e. during 6 months prior to the last interview. Both effects are expected to be negative, i.e. that (non) victimization anticipates (non)victimization. Given the large proportion of nonrespondents in the complement category of 'non-victim', the estimated coefficients would give the minimum such effect on current victimization incidence. Indeed, the majority of individuals, who do not belong to the category of prior non-victim, did not participate in the NCVS during the corresponding periods. They are more likely that

TABLE 3 Prior personal victimization (observed values [percent of the total])

\begin{tabular}{|c|c|c|c|c|c|c|c|c|c|c|}
\hline \multirow{3}{*}{$\begin{array}{l}\text { Wave } 1 \\
\text { Non victim }\end{array}$} & \multicolumn{10}{|c|}{ Wave 2} \\
\hline & \multicolumn{2}{|c|}{ Non victim } & \multicolumn{2}{|c|}{ Victim } & \multicolumn{2}{|l|}{ Missing } & \multicolumn{2}{|l|}{ Other } & \multicolumn{2}{|l|}{ Total } \\
\hline & 3,912 & $(4.5)$ & 44 & $(0.1)$ & 0 & & 44 & $(0.1)$ & 3,956 & $(4.5)$ \\
\hline Victim & 47 & $(0.1)$ & 0 & & 0 & & 0 & & 47 & $(0.1)$ \\
\hline Missing & 57,116 & $(65.7)$ & 881 & $(1.0)$ & 24,999 & $(28.7)$ & 25,880 & $(29.7)$ & 82,996 & $(95.4)$ \\
\hline Other & 57,163 & $(65.7)$ & 881 & (1.0) & 24,999 & $(28.7)$ & 25,880 & (29.7) & 83,043 & $(95.5)$ \\
\hline Total & 61,075 & $(70.2)$ & 925 & (1.1) & 24,999 & $(28.7)$ & 25,924 & (29.8) & 86,999 & $(100.0)$ \\
\hline
\end{tabular}

\footnotetext{
${ }^{6}$ This attrition is not simply due to new sample acquisition.
} 
not, to have not been victimized during the periods they were missing from the survey. Thus prior non-victimization effects are based on a subset of actual prior non-victims and are therefore underestimated. ${ }^{7}$

\section{Measured heterogeneity}

What characteristics should be incorporated in models of personal victimization? Attributes of the individuals and their households from the third wave of the 1994 NCVS were chosen drawing upon routine activity or lifestyle theory (Hindelang et al. 1978; Cohen and Felson 1979; Felson 1998) and previous empirical research evidence (for example Kennedy and Forde 1990; Miethe and Meier 1990; Tseloni 2000).

Proponents of both theories argue that the demographic and socio-economic characteristics of individuals and their households as well as their lifestyle patterns and everyday routine activities together determine their exposure to crime. With respect to personal crime, they do so, inter alia, by influencing individuals' chances of coming into contact with motivated offenders in the absence of effective guardians. While lifestyle affects one's exposure to criminal victimization opportunities, the effects of demographic and socio-economic characteristics are mediated through socializing. Insofar as people share characteristics with potential offenders, they face increased risk of victimization. From an offender's perspective, personal and household characteristics and lifestyles contribute to determining target suitability and desirability.

The personal characteristics, which we incorporate in this study, comprises of sex, age, race, marital status, lone parenthood, educational level, employment status and length of residence at the same address, together with lifestyle indicators, such as shopping, evenings out and use of public transportation. All the above are defined at the individual level (level 1) of the statistical model below. Household characteristics, which are defined at level 2, include household composition, ${ }^{8}$ number of cars, household annual income, type of tenure, and devices against intruders. Living in an urban area and place size in terms of population despite being area characteristics are also defined at level 2.

The set of personal and household characteristics related to victimization indicate measured individual and household heterogeneity, respectively. Our indicators of event dependence (see the section on indicators of event dependence), namely prior nonvictimization by personal crime at waves $1(12<18$ months prior to the reference period) and $2(6<12$ months prior to the reference period), refer to the individual and are thus defined at level 1 . Table 4 describes the set of explanatory variables. Its last row gives the total number of valid cases in the study. Educational level, household composition, tenure and devices against intruders were dropped from the final models below due to lack of statistical significance in their effects on victimization in wave 3 .

\footnotetext{
${ }^{7}$ Measurement error in a variable is likely to result in a biased towards zero respective coefficient (Greene 2000).

${ }^{8}$ Number of adults and children in the household were used in the original models.
} 
REPEAT PERSONAL VICTIMIZATION

Table 4 Description of covariates

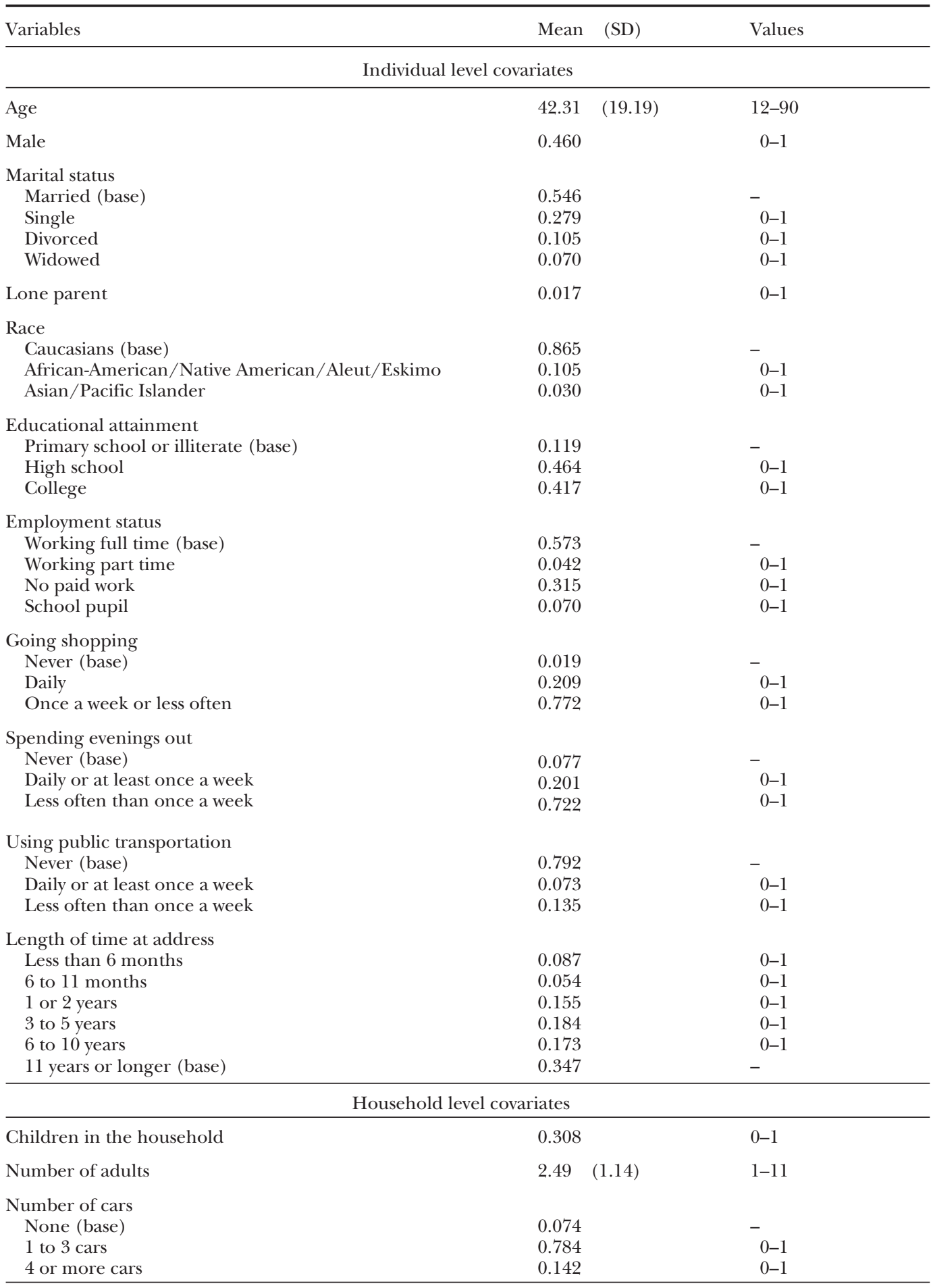


TSELONI AND PEASE

TABLE 4 continued

\begin{tabular}{|c|c|c|}
\hline Variables & Mean (SD) & Values \\
\hline \multicolumn{3}{|c|}{ Household level covariates } \\
\hline \multicolumn{3}{|l|}{ Household annual income } \\
\hline Less than $\$ 10,000$ & 0.116 & $0-1$ \\
\hline$\$ 10,000-\$ 49,999$ (base) & 0.547 & - \\
\hline$\$ 50,000$ or more & 0.227 & $0-1$ \\
\hline Refused to answer & 0.110 & $0-1$ \\
\hline Own house or apartment & 0.286 & $0-1$ \\
\hline Devices against intruders & 0.658 & $0-1$ \\
\hline Urban & 0.721 & $0-1$ \\
\hline \multicolumn{3}{|l|}{ Place size } \\
\hline 24,999 or less (base) & 0.587 & - \\
\hline $25,000-249,999$ & 0.262 & $0-1$ \\
\hline 250,000 or more & 0.151 & $0-1$ \\
\hline \multicolumn{3}{|c|}{ Prior non-victim by personal crime (individual level) } \\
\hline Non-victim of personal crime at wave 1 & 0.045 & $0-1$ \\
\hline Non-victim of personal crime at wave 2 & 0.702 & $0-1$ \\
\hline Number of cases & 86,999 & \\
\hline
\end{tabular}

\section{The Statistical Model}

Goldstein (1995) describes multilevel models for proportions, presenting models for counts only as an extension of the former. The negative binomial regression model derives as a compound Poisson. Let us first define the multilevel Poisson model.

Let $\mu_{i j}$ be the expected number of personal victimizations. The log link function for the Poisson model with random intercept is

$$
\begin{aligned}
& \ln \mu_{i j}=n_{i j}=X_{i} \beta+u_{0 j} \quad i=1, \ldots, 11, j=1, \ldots, H \\
& E\left(u_{0 j}\right)=0 \\
& \operatorname{Var}\left(u_{0 j}\right)=\sigma_{u 0}^{2}
\end{aligned}
$$

where $u_{0 j}$ is the household level error term associated with the intercept; $X_{i j}$ is a row vector of the set of covariates for the $i j$-th individual including the intercept; $\beta$ is a vector of fixed coefficients including the fixed part of the intercept.

The probability distribution for $Y_{i j}$ follows the Poisson. Thus the probability that $Y_{i j}$ takes the specific value $y_{i j}$ is

$$
\operatorname{Pr}\left(Y_{i j}=y_{i j}\right)=\exp \left(-\mu_{i j}\right)\left(\mu_{i j}\right)^{y_{i j}} / y_{i j} !, \quad y_{i j}=0,1, \ldots
$$

This model, where $E\left(Y_{i j}\right)=\operatorname{var}\left(Y_{i j}\right)=\mu_{i j}$, is clearly not applicable here (see Table 2 ).

The negative binomial regression model allows for between individual random variation in the expected number of events $\mu_{i j}$ in (2).

$$
\ln \lambda_{i j}=n_{i j}+e_{i j}
$$


where $\exp \left(e_{0 i j}\right)$ follows a gamma probability distribution $\Gamma(v)$, with $E\left\{\exp \left(e_{0 i j}\right)\right\}=1$ and $\operatorname{var}\left\{\exp \left(e_{0 i j}\right)\right\}=\alpha=v^{-1}$ (Cameron and Trivedi 1986).

Integrating with respect to $e_{i j}$ the probability distribution which results from combining (3) and (2) we obtain one version ${ }^{9}$ of the multilevel negative binomial model (MNBM II) with random intercept.

$$
\operatorname{Pr}\left(Y_{i j}=y_{i j}\right)=\left\{\Gamma\left(y_{i j}+v\right) v^{v}\left(\lambda_{i j}\right) y^{i j}\right\} /\left\{y_{i j} ! \Gamma(v)\left(v+\lambda_{i j}\right)^{v+y i j}\right\} \quad y_{i j}=0,1, \ldots
$$

The MNBM II gives the same expected mean of personal crimes as the multilevel Poisson above, $E\left(Y_{i j}\right)=\lambda_{i j}=\exp \left(n_{i j}\right)$. Its variance is given by

$$
\operatorname{var}\left(Y_{i j}\right)=\lambda_{i j}+\alpha \lambda^{2} i j
$$

allowing for overdispersion. Indeed the extra-Poisson variation at level 1 is defined by $\alpha$ (with $\alpha>0$ ) and $\lambda^{2} i$. $\alpha$ gives the coefficient of overdispersion and $v$ is the precision parameter (Cameron and Trivedi 1986; Osborn and Tseloni 1998). Overdispersion in our models derives from unexplained heterogeneity between individuals (Osborn and Tseloni 1998: 308).

In the MNBM II the intra-household correlation is calculated as

$$
\rho=\sigma_{u 0}^{2} /\left(\sigma_{u 0}^{2}+\alpha\right)
$$

It gives the correlation of the mean number of personal crimes between two individuals in the same household (Goldstein 1995: 19) and, as mentioned, implies persistent household unexplained heterogeneity.

The estimated models below have been obtained using iterative generalized least squares (IGLS) estimation with first order marginal quasi-likelihood (MQL) approximation via the software package MLwiN (Goldstein et al. 1998).

\section{Results}

Fixed effects

As mentioned, our aim is to test the importance of heterogeneity and event dependence on personal victimization. To this end we estimated three MNBM II models with random intercept and a baseline with just the intercept (see the section 'Unexplained heterogeneity' and Table 6 below). Model 1 includes only the two indicators of prior non-victimization. Model 2 includes only measured heterogeneity, i.e. the set of personal and household characteristics as well as lifestyle indicators that are related to crime. A final Model 3 has resulted by adding prior non-victimization to Model 2. Table 5 presents the estimated fixed effects of the above empirical models together with an indication of the statistical significance of their coefficients. In the rows below each set of variables, namely individual characteristics, household attributes and prior non-victimization, joint $\chi^{2}$ tests for the respective fixed effects with their appropriate degrees of freedom are also given. In comparison with $\chi^{2}$ distributions with 22, 8 and 2 degrees of freedom respectively, the

\footnotetext{
${ }^{9}$ There are more than one specifications of the negative binomial model. This is the multilevel version of the negative binomial model Negbin II (Cameron and Trivedi 1986, p. 33).
} 
TSELONI AND PEASE

TABLE 5 Multilevel negative binomial models of personal victimisation

\begin{tabular}{|c|c|c|c|}
\hline & Model 1 & Model 2 & Model 3 \\
\hline \multicolumn{4}{|c|}{ Estimated individual level fixed effects (s.e.) } \\
\hline \multicolumn{4}{|c|}{ Individual characteristics } \\
\hline Age & & $-0.036^{*}$ & $-0.036^{*}$ \\
\hline Male & & $0.341 *$ & $0.339 *$ \\
\hline \multicolumn{4}{|l|}{ Marital status (married) } \\
\hline Single & & $0.331 *$ & $0.329 *$ \\
\hline Divorced & & $0.844 *$ & $0.842 *$ \\
\hline Widowed & & $0.323^{\wedge}$ & $0.324^{\wedge}$ \\
\hline Lone parent & & $0.566^{*}$ & $0.569 *$ \\
\hline \multicolumn{4}{|l|}{ Race (Caucasian) } \\
\hline African-American/Native American/Aleut/Eskimo & & -0.060 & -0.059 \\
\hline Asian/Pacific Islander & & -0.572 & -0.571 \\
\hline \multicolumn{4}{|l|}{ Employment status (Working full time) } \\
\hline Working part time & & $0.463 *$ & $0.458 *$ \\
\hline No paid work & & -0.092 & -0.088 \\
\hline School pupil & & -0.036 & -0.048 \\
\hline \multicolumn{4}{|c|}{ Individuals' lifestyle } \\
\hline \multicolumn{4}{|l|}{ Shopping (never) } \\
\hline Daily & & $0.543^{\sim}$ & $0.549^{\sim}$ \\
\hline Once a week or less often & & 0.144 & 0.150 \\
\hline \multicolumn{4}{|l|}{ Evenings out (never) } \\
\hline Daily & & $0.287^{\sim}$ & $0.285^{\sim}$ \\
\hline Once a week or less often & & -0.059 & -0.058 \\
\hline \multicolumn{4}{|l|}{ Public transportation (never) } \\
\hline Daily or at least once a week & & $0.450 *$ & $0.446 *$ \\
\hline Less often than once a week & & $0.345^{*}$ & $0.343^{*}$ \\
\hline \multicolumn{4}{|c|}{ Length of time at address (11 years or longer) } \\
\hline Less than 6 months & & $0.587 *$ & $0.698 *$ \\
\hline 6 to 11 months & & $0.554 *$ & $0.490 *$ \\
\hline 1 or 2 years & & $0.289 *$ & $0.268^{*}$ \\
\hline 3 to 5 years & & 0.059 & 0.059 \\
\hline 6 to 10 years & & $0.177^{\sim}$ & $0.172^{\sim}$ \\
\hline Joint $\chi^{2}$ test of individual level fixed effects & & $1,174.263$ & $1,020.401$ \\
\hline Degrees of freedom & & 22 & 22 \\
\hline \multicolumn{4}{|c|}{ Estimated household level fixed effects (s.e.) } \\
\hline \multicolumn{4}{|c|}{ Household characteristics } \\
\hline \multicolumn{4}{|l|}{ Number of cars (none) } \\
\hline 1 to 3 cars & & -0.068 & -0.070 \\
\hline 4 or more cars & & 0.320 & $0.313^{\sim}$ \\
\hline \multicolumn{4}{|l|}{ Annual income $(\$ 10,000-\$ 49,999)$} \\
\hline Less than $\$ 10,000$ & & $0.200^{\sim}$ & $0.193^{\sim}$ \\
\hline$\$ 50,000$ or more & & -0.011 & -0.017 \\
\hline Refused to answer & & -0.063 & -0.081 \\
\hline
\end{tabular}


TABLE 5 continued

\begin{tabular}{|c|c|c|c|}
\hline & Model 1 & Model 2 & Model 3 \\
\hline \multicolumn{4}{|c|}{ Estimated household level fixed effects (s.e.) } \\
\hline \multicolumn{4}{|c|}{ Area characteristics } \\
\hline Urban & & $0.250 *$ & $0.250 *$ \\
\hline $\begin{array}{l}\text { Place size }(24,999 \text { or less }) \\
25,000-249,999 \\
250,000 \text { or more }\end{array}$ & & $\begin{array}{l}0.178^{*} \\
0.199^{\sim}\end{array}$ & $\begin{array}{l}0.173^{*} \\
0.199^{\sim}\end{array}$ \\
\hline $\begin{array}{l}\text { Joint } \chi^{2} \text { test of household level fixed effects } \\
\text { Degrees of freedom }\end{array}$ & & $\begin{array}{l}65.434 \\
8\end{array}$ & $\begin{array}{l}64.734 \\
8\end{array}$ \\
\hline \multicolumn{4}{|c|}{ Estimated individual level fixed effects (s.e.) } \\
\hline \multicolumn{4}{|c|}{ Prior non-victim by personal crime (individual level) } \\
\hline $\begin{array}{l}\text { No personal victimisation at wave } 2 \\
\text { No personal victimisation at wave } 1\end{array}$ & $\begin{array}{l}-0.764 * \\
-0.718 *\end{array}$ & & $\begin{array}{l}-0.188 * \\
-0.602 *\end{array}$ \\
\hline $\begin{array}{l}\text { Joint } \chi^{2} \text { test of prior non-victimisation fixed effects } \\
\text { Degrees of freedom }\end{array}$ & $\begin{array}{l}251.186 \\
\quad 2\end{array}$ & & $\begin{array}{l}22.995 \\
2\end{array}$ \\
\hline
\end{tabular}

Note: The number of observations is 86,999 .

* Statistically significant at $\mathrm{p}$ value $<0.01$.

$\sim$ Statistically significant at $\mathrm{p}$ value $<0.05$.

$\wedge$ Statistically significant at $\mathrm{p}$ value $<0.10$.

corresponding individual, household and prior non-victimization fixed effects are highly statistically significant, implying that each set of covariates adds important information for the prediction of personal crimes.

In Model 1 prior non-victimization at waves 2 and 1 seems to reduce current mean personal crime by 53 and 51 per cent, respectively. After accounting for lifestyle and personal and household characteristics however, prior non-victimization, especially for the adjacent period (wave 2) to the reference period, seems to affect current personal crime incidence less than when measured heterogeneity is omitted (see Models 1 and 3 ). In particular, prior non-victimization during $6<12$ and $12<18$ months before the reference period reduces current personal crime incidence by 17 and 45 per cent, respectively (Model 3). It is worth noting that the statistical significance of the two indicators of event dependence has remained high. Thus some event dependence is due to concealed heterogeneity, especially across adjacent periods when individuals' attributes and lifestyle are most likely to remain the same. As noted above, when we account explicitly for measured heterogeneity in Model 3, the effect of prior non victimization in wave 2 is reduced from 53 per cent (Model 1) to 17 per cent. This reduction implies that the coefficient was overestimated in Model 1 and the indicator accounted for more than prior non-victimization in wave 2 , namely the omitted indicators of measured heterogeneity. The substantive implications of this are discussed in the section concerning unexplained heterogeneity and in the conclusions below.

The fixed effects of the indicators of measured heterogeneity remained essentially the same after introducing prior non-victimization (see Models 2 and 3). This implies that the estimated effects of measured heterogeneity do not entail any event dependence 
when the latter is not accounted for in the models. The following paragraphs describe the fixed effects of such indicators based on the results of Model 3.

The expected number of personal crimes one may experience during the reference period of six months varies according to demography. It decreases by 4 per cent for every year one ages. Considering gender, it is 40 per cent greater for males than females. Single, divorced, or widowed people face respectively 39, 132 and 38 per cent more personal crimes than the married. Lone parents face 77 per cent more such crimes than other people. People of Asian or Pacific Island origin experience 44 per cent fewer personal crimes than Caucasians. Consistent with recent previous research (Lauritsen and Sampson 1998; Tseloni 2000) African Americans and others do not seem to be at altered risk of personal crime relative to Caucasians. People working part-time have a 58 per cent higher expected mean rate of victimization by personal crime than those working full-time.

Shopping daily (compared with never), or spending each evening out (relative to no evening out), increases personal crime incidence by 73 and 33 per cent, respectively. Using public transportation is linked to more personal crimes ( 56 and 41 per cent for those using it more or less often than once a week, respectively).

There is a gradual decrease in the number of personal crimes one is expected to experience the longer she/he has lived at the same address. Indeed, period at present residence of 6 to 10,1 to 2 years, 6 to 11 months or less than six months is related to respectively $19,31,63$, and 101 per cent more personal crimes suffered compared to an individual who has lived at the same address for at least 11 years.

Individuals in households owning four or more cars suffer 37 per cent more personal crimes than those with none. Low household income (less than $\$ 10,000$ per year) increases the rate of suffering personal crimes by 21 per cent compared to the base category of $\$ 10,000-49,999$ while earning $\$ 50,000$ or more does not differentially affect personal victimization relative to $\$ 10 \mathrm{~K}<50 \mathrm{~K})$. Living in an urban area of population between 25,000 and 249,999 or 250,000 or more is associated with respectively 28, 19 and 22 per cent more personal crimes compared to the base categories (of non urban and population less than 24,999 people).

The above results agree with previous research on personal crime victimization (Kennedy and Forde 1990; Miethe and Meier 1990; Tseloni 2000) and generally support the routine activity or lifestyle theory (Cohen and Felson 1979; Felson 1998; Hindelang et al. 1978).

\section{Unexplained Heterogeneity}

As mentioned earlier (in 'The Statistical Model') our models are multilevel with random intercept, whereby any random variation of the dependent variable, here the mean number of personal crimes, is only attributed to the intercept. The coefficients of the covariates, the 'slopes', remain constant. Table 6 presents the estimated intercepts and related random components for each model of this study including the baseline model with only a random intercept. As mentioned, ${ }^{\wedge} \sigma^{2}{ }_{u 0}$ represents the between households estimated random variation of the mean number of personal crimes, ${ }^{\wedge} \alpha$ is its between individual estimated random variation and ${ }^{\wedge} \rho$ is the intra-household correlation (see 'The Statistical Model' above). 
REPEAT PERSONAL VICTIMIZATION

TABLE 6 Intercept and its random components

\begin{tabular}{|c|c|c|c|c|}
\hline \multirow[t]{2}{*}{ Models } & \multirow[t]{2}{*}{ Constant } & \multicolumn{2}{|c|}{ Random variation } & \multirow{2}{*}{$\begin{array}{l}\text { Intra-household } \\
\text { correlation } \wedge \rho\end{array}$} \\
\hline & & $\begin{array}{l}\text { Between } \\
\text { households } \\
{ }^{\wedge} \sigma_{\mathrm{u} 0}^{2}\end{array}$ & $\begin{array}{l}\text { Between } \\
\text { individuals } \\
{ }^{\wedge} \alpha\end{array}$ & \\
\hline Baseline & -3.615 & 3.074 & 13.331 & 0.187 \\
\hline Fixed effects of priors (Model 1) & -3.126 & 2.560 & 12.221 & 0.173 \\
\hline $\begin{array}{l}\text { Fixed effects of individual, } \\
\text { household, area and lifestyle } \\
\text { (Model 2) }\end{array}$ & -3.761 & 2.159 & 6.969 & 0.236 \\
\hline $\begin{array}{l}\text { Fixed effects of all the above } \\
\text { (Model 3) }\end{array}$ & -3.597 & 2.069 & 6.915 & 0.230 \\
\hline
\end{tabular}

All estimates are statistically significant at $\mathrm{p}$ value $<0.01$.

The exponent of the intercept is the mean number of personal crimes experienced by the reference individual who belongs to the reference household, that is one with all the base categories of the models' covariates and (for Models 2 and 3) of zero age. Thus the mean number of personal crimes is 0.027 per six months for the baseline model when no individual attributes, i.e. measured heterogeneity, or event dependence are considered. This estimate is very close to the mean of the observed distribution of personal crimes (see Table 2). Personal crime incidence is 0.044 for an individual who either did not participate in the 1994 NCVS for more than one wave or, if she/he had, reported prior personal victimization (Model 1).

To interpret the intercept of Models 2 and 3 in a meaningful way, one must express risks relative to a benchmark person. The mean age of the sample is 42 years. Thus the expected number of personal crimes for a 42-year-old married, white female who works full time, never goes shopping, nor spends any evenings out nor uses public transportation, has lived at the same address of a non-urban area of less than 25,000 people for at least 11 years, whose household does not own a car, but earns $\$ 10,000-49,999$ per annum is 0.005 (calculated from Model 2 as $\{\exp [-3.761-(0.036 * 42)]\}$ ). If, additionally, she participated only in wave 3 of the 1994 NCVS or, having participated in the previous ones she reported prior personal victimization she faces on average 0.006 personal crimes (Model 3).

Introducing prior non-victimization essentially does not reduce the random variation of the intercept, namely unexplained heterogeneity (compare Model 1 to baseline and Model 3 to 2). On the other hand allowing for fixed effects of individual, household and lifestyle covariates in the models nearly halves unexplained heterogeneity between individuals and reduces the between household random variation by roughly one third. Therefore unexplained heterogeneity does not essentially entail any event dependence but rather unmeasured characteristics of the individuals, their social and physical environment and/or their lifestyle. That prior (lack of) victimization effects diminish when measured heterogeneity is included in the models (see the section 'Fixed effects' above) reducing thus unexplained variation implies that event dependence is contingent on what is elusive about the individual. The opposite direction of effects, i.e. from event dependence to unexplained heterogeneity, is clearly not evidenced here. The notion 
that event dependence is triggered by non-obvious characteristics of victims is consistent with both intuition and interviews with offenders (see for example Ashton et al. 1998). A burglar can see dwelling characteristics but not a safe in the bedroom. A would-be assailant can tell a victim's age but not her possession of martial arts skills. The interplay between characteristics that come to light only after a first crime (likely to involve unmeasured heterogeneity) and which inform the offender's taste for repetition (event dependence) is very close. This is an extremely important point, which will be developed somewhat in the conclusion.

Interestingly the estimated persistent household unexplained heterogeneity is modest (see last column of Table 6). Roughly 20 per cent of the total variation is between households. The ${ }^{\wedge} \rho$ remains essentially the same from introducing prior nonvictimization and/or covariates of measured heterogeneity in the models. There is only an indication of increasing correlation between two individuals from the same household when individual, household, area and lifestyle covariates are explicitly accounted for in the models (compare baseline and Model 1 to Models 2 and 3, respectively). This implies that two individuals with identical personal, household and area characteristics as well as lifestyle patterns (represented by the set of covariates in our study) face different expected personal crimes due simply to their membership of different households.

\section{Conclusions}

There are limits to the generalizability of this paper, not least because of the limits which mobility of households puts on the data. With the data at hand, it seems that explained and unexplained heterogeneity at the individual and household level both contribute substantially to explain variation in the levels of personal victimization. They do not exhaust it. There is thus a non-trivial component of event dependence, which is greater over the long than the short term (see also point 2 below) when explained heterogeneity is also present. The opposite relative size of effects is observed when it is not. What does this mean for the enterprise of crime reduction based on responses to prior victimization? There are four implications.

(1) Insofar as victimization is based on personal and household characteristics which are easy to measure and often form part of publicly accessible data about households, it is possible to prioritize people and households for preventive attention. These characteristics can be thought of as readily visible flags. The relevance of prioritization of preventive effort on the basis of such flags is clear for property crime. While theoretically possible for personal crimes, it is difficult to envisage realistic programmes to do this, at least outside special contexts, such as school anti-bullying enterprises, whereby individuals can realistically be targeted as having high prior probabilities of victimization.

(2) Insofar as victimization is based upon variables which are more elusive, victimization is a marker for less visible flags. Thus the demonstration of the substantial role of unexplained heterogeneity is, paradoxically, a reason at least in the medium term, for treating crime victims as having priority for preventive effort. However, as noted in the opening section of this paper, this is an unsatisfactory state of 
affairs in terms of both theory and practice. There is a case for a research effort to identify enduring characteristics that distinguish those with identical known crime-linked characteristics in terms of victimization experience. This would be the obvious research response to the picture revealed by this and earlier papers.

(3) Insofar as victimization is event-dependent, treating crime victims as having priority for preventive work is clearly desirable. The hope would be that insofar as the sources of unexplained heterogeneity comes to be understood, the attention giving to helping prior victims would diminish in importance. This diminution would occur as victimization as a symptom of unknown enduring characteristics became less necessary. When a crime no longer has to do service in alerting us to a state of affairs we do not otherwise understand, the emphasis on preventing repeated victimization can decline.

(4) Event dependence is contingent upon an offender's awareness of subtle differences between people or households, which differences would contribute to unmeasured heterogeneity. This close linkage between event dependence and unmeasured heterogeneity is important in two ways. First, it emphasizes the importance of change after a crime so that an offender's presumption that the person or place is as he or she left it is challenged. The other is to change the presumption of an offender about the likely state of one aspect of unmeasured heterogeneity. This is relevant to first offences against a target as well as repeats. For example, at what level of coverage of a vehicle fleet by Lo-Jack/Tracker does an offender presume that a targeted vehicle is protected? At what level of penetration of covert alarms in the homes of victims of domestic violence does a perpetrator assume that an individual home is covered? Put generally, how do we change an offender's presumption about a non-obvious victim attribute? Experience during a first offence shapes the presumption for a repeat. Assumed base rates shape the presumption for the first offence against a target. Shaping that presumption, by publicity or visual cues, may be productive in preventing crime.

\section{REFERENCES}

Ashton, J., Senior, B., Brown, I. and Pease, K. (1998), 'Repeat Victimization: Offender Accounts', International Journal of Risk, Security and Crime Prevention, 3: 269-80.

Bryk, A. S. and Raudenbush, S. W. (1992), Hierarchical Linear Models: Applications and Data Analysis Methods. Newbury Park: Sage.

Cameron, C. A. and Trivedi, P. K (1986), 'Econometric Models Based on Count Data: Comparisons and Application of Some Estimators and Tests', Journal of Applied Econometrics, 1: 29-53.

Cohen, L. E. and Felson, M. (1979), 'Social Change and Crime Rates and Trends: A Routine Activity Approach', American Sociological Review, 44: 588-608.

Ellingworth, D. E., Farrell, G. and Pease, K. (1995), 'A Victim is a Victim is a Victim? Chronic Victimization in Four Sweeps of the British Crime Survey', British Journal of Criminology, 35: $360-5$.

Farrell, G. (1992), 'Multiple Victimization: Its Extent and Significance', International Review of Victimology, 2: 85-102.

Farrell, G. and Pease, K. (2001), Repeat Victimization. Monsey NY: Criminal Justice Press. 
Felson, M. (1998), Crime and Everyday Life, 2nd edn. Thousand Oaks, CA: Pine Forge Press.

Goldstein, H. (1995), Multilevel Statistical Models, 2nd edn. London: Arnold.

Goldstein, H., Rasbash, J., Plewis, I., Draper, D., Browne, W., Yang, M., Woodhouse, G. and Healy, M. (1998), A User's Guide to MLwiN. London: Institute of Education.

Greene, W. H. (2000), Econometric Analysis, 4th edn. NJ: Prentice Hall.

Hindelang, M., Gottfredson, M. R. and Garofalo, J. (1978), Victims of Personal Crime: An Empirical Foundation for a Theory of Personal Victimization. Cambridge: Ballinger.

Kennedy, L. W. and Forde, D. R. (1990), 'Routine Activities and Crime: An Analysis of Victimization in Canada', Criminology, 28: 137-52.

Lauritsen, J. L. and Davis-Quinet, K. F. (1995), 'Repeat Victimization among Adolescents and Young Adults', Journal of Quantitative Criminology, 11: 143-66.

Lauritsen, J. L. and Sampson, R. (1998), 'Victimization Risk across Ecological Contexts: Individual and Community Effects in the National Crime Victimization Survey', paper presented at the American Society of Criminology Meeting, Washington, DC, November.

Lynch, J. and Tseloni, A. (2001), As Simple as Possible and No Simpler: Cross-National Comparisons of Self-Report Victimization Surveys, submitted manuscript.

McGullagh, P. and Nelder, J. A. (1989), Generalized Linear Models, 2nd edn. London: Chapman and Hall.

Miethe, T. D. and Meier, R. F. (1990), 'Opportunity, Choice, and Criminal Victimization: A Test of a Theoretical Model', Journal of Research in Crime and Delinquency, 27: 243-66.

Osborn, D. R. and Tseloni, A. (1998), 'The Distribution of Household Property Crimes', Journal of Quantitative Criminology, 14: 307-30.

Pease, K. (1998), Repeat Victimization: Taking Stock, Crime Prevention Series Paper 90. London: Home Office.

Pease, J., Pease, K. and Tseloni, A. (2001), Investigating Transition Probabilities and Overdispersion in the Crime Distributions, working paper.

Tseloni, A. (2000), 'Personal Victimization in the United States: Fixed and Random Effects of Individual and Household Characteristics', Journal of Quantitative Criminology, 16: 415-42.

Wittebrood, K. and Nieumbeerta, P. (2000), 'Criminal Victimization during One's Life-Course: The Effects of Previous Victimization and Patterns of Routine Activities', Journal of Research in Crime and Delinquency, 37: 91-122. 